\title{
A Educação Física: da crise geral para algumas crises particulares
}

\author{
Silvia Christina Madrid Finck ${ }^{1}$
}

\begin{abstract}
RESUMO
O texto aborda alguns aspectos da crise da Educação Física, a qual gerou a instalação da polêmica pela classe acadêmica e científica a partir da década de oitenta. Evidencia-se que tal crise não é específica, mas também encontra-se na escola, nos diferentes sistemas e na sociedade.

Palavras-chave: sociedade, educação, crise, escola, educação física, educação física escolar

A Sociedade é formada por diferentes sistemas, entre os quais, o educacional, o econômico e o social e como um todo sofre constantes transformações, em que ocorrem melhorias, mas também problemas. Tais sistemas estão inter-relacionados e dependem uns dos outros, tendo cada qual sua complexidade específica, assim como suas necessidades e dificuldades.

O sistema educacional, na sua complexidade, depende dos sistemas econômico e social que o geram e o determinam. Os problemas de cada um refletem-se nos demais, como uma engrenagem, onde as partes têm que estar em atividade para que o todo funcione. "A educação não pode ser analisada abstratamente, mas sim condicionada e condicionante de uma sociedade determinada." ${ }^{2}$
\end{abstract}

\footnotetext{
${ }^{1}$ Mestre em Educação pela UNIMEP - Doutoranda em Ciência da Atividade Física e do Esporte - Universidade de Léon - Espanha. Professora Assistente na área de Metodologia e Prática de Ensino de Educação Física da UEPG. Professora de Educação Física da Rede Pública de Ensino do Estado do Paraná no ensino fundamental e médio.

${ }^{2}$ CUNHA, D. A. As utopias na educação. Rio de Janeiro, RJ: Paz e Terra, 1985, p.15

Olhar de professor, Ponta Grossa, 2 (2):181-193, nov. 1999.
} 
A Educação dos indivíduos de uma sociedade interfere no seu desenvolvimento, sendo que, nos indicadores de desenvolvimento da O.N.U. (Organização das Nações Unidas), é amplamente reconhecido que existe uma ligação estreita entre educação, progresso econômico e social.

É falsa a afirmação de que nada é possivel fazer na educação enquanto não houver uma transformação da sociedade, porque a educação é dependente da sociedade. A educação não é, certamente, a alavanca da transformação social. Porém, se ela não pode fazer sozinha a transformação, essa transformação não se consolidará sem ela. ${ }^{3}$

A ação educativa se dá nas relações entre as pessoas, nas mais diferentes formas, nos mais diferentes lugares, acontecendo de forma constante na sociedade. Não se pode deixar de lado o fato de que não existe um modelo único de Educação, a escola não é o único lugar onde se educa e o professor não é o único educador. Independentemente de quem e onde se educa, é possível dizer que a Educação é uma ação eminentemente humana e social.

Considerando a Educação num sentido amplo, uma multiplicidade de instâncias sociais legítimas entre elas: a família, a religião, a empresa, o clube, os partidos políticos e os meios de comunicação - envolvem o sistema educacional e interferem na sua efetivação, sendo responsáveis pela transformação da sociedade.

Seria muita pretensão afirmar que é competência apenas da Escola e da Educação a transformação da sociedade, pois é ao conjunto da sociedade que se confere esse poder. Porém, o que se pode e se deve fazer, enquanto educador compromissado, é sintonizar a escola com o movimento social mais amplo de transformação da sociedade. "Se a escola é parte integrante do todo social, agir dentro dela é também agir no rumo da transformação da sociedade." 4

Uma boa escolarização pode contribuir para que o educando adquira uma visão de mundo menos mística e folclórica, tornando-se assim um ponto de partida para um conhecimento crítico da sociedade. O profissional da Educação desempenha um papel importante nesse sentido e sua competência (formação, consciência política, comprometimento com a maioria dos educandos) está diretamente relacionada com a garantia de uma boa escolarização.

A Educação, enquanto fenômeno social, tem evidenciado duas funções opostas: de um lado, a conservadora;

\footnotetext{
${ }^{3}$ GADOTTI, Moacir. Educação e Poder: Introdução à Pedagogia do Conflito. São Paulo, SP : Cortez: Autores Associados, 1984. p.63.

${ }^{4}$ LIBÂNEO, José Carlos. A Democratização da Escola Pública: a pedagogia crítico-social dos conteúdos. $9^{\mathrm{a}}$ ed. São Paulo: SP : Loyola, 1990, p.39
} 
de outro, a renovadora. A função conservadora da Educação torna-se evidente, consistindo num processo de transmissão das tradições ou da cultura de um grupo, de uma geração à outra. Já a função renovadora da Educação visa a promoção do ser humano e, portanto, são suas necessidades que determinam os objetivos educacionais, as quais devem ser consideradas de forma concreta, pois a ação educativa é sempre desenvolvida num contexto existencial. ${ }^{5}$

Assim sendo, de acordo com a função renovadora da Educação, as necessidades e a realidade de cada comunidade deveriam ser levadas em consideração, na elaboração e execução do planejamento educacional, para que a Educação realmente tivesse significância e cumprisse sua função. Tal função está relacionada com a modificação e enriquecimento da realidade do indivíduo, suprindo necessidades diferenciadas e específicas.

Segundo Dias, o sistema escolar "[...] cuida de um aspecto especial da educação a que se poderia chamar escolarização." À Escola compete a maior parte da orientação para o saber sistematizado, cumprindo funções que lhe são dadas pela sociedade (his- toricamente), a qual se apresenta constituída por classes com interesses divergentes.

A prática escolar apresenta condicionantes sócio-políticos que caracterizam e revelam diferentes concepções de homem e de sociedade. Portanto, em cada formação social e em cada época, a prática educacional apresenta características próprias e cumpre funções específicas. Para Freitag,

todos os autores que tratam da educação num contexto social concordam que 'a educação sempre expressa uma doutrina pedagógica, a qual, implícita ou explicitamente, se baseia em uma filosofia de vida, concepção de homem e sociedade. ${ }^{7}$

A Escola tem sofrido nas últimas décadas inúmeras críticas, tanto por parte da sociedade quanto por parte dos educadores. Através de dados comprovados, há evidencias de que não tem correspondido às necessidades da sociedade. Aquilo que é transmitido e considerado como essencial, muitas vezes, está distante do que a comunidade escolar espera e preci-

${ }^{5}$ AZEVEDO (1964), SAVIANI (1982). Apud, José Guilmar Mariz de OLIVEIRA, Mauro BETTI, Wilson Mariz de OLIVEIRA. Educação Física e o Ensino de $1^{\circ}$ grau: Uma abordagem crítica. São Paulo, SP: EPU-EDUSP, 1988. p. 2-3.

${ }^{6}$ DIAS, J. A. Apud, Ibid., p.5.

${ }^{7}$ Apud, José Guilmar Mariz de OLIVEIRA, Mauro BETTI, Wilson Mariz de OLIVEIRA, op.cit., p.31.

${ }^{8}$ José Guilmar Mariz de OLIVEIRA, Mauro BETTI, Wilson Mariz de OLIVEIRA, op. cit., p. 31. 
sa, certamente por não se considerar,

[...] que o processo educacional se dá numa situação concreta, dirige-se a indivíduos particulares, num determinado contexto histórico. ${ }^{8}$

O enorme índice de evasão escolar, a repetência em massa, a péssima qualidade de ensino, o salário irrisório dos professores, os milhões de brasileiros analfabetos, enfim, o caos da educação brasileira revela que a escola não está cumprindo sua função social.

Constata-se que a escola não tem cumprido de forma satisfatória seus objetivos. Enquanto instituição responsável pela transmissão do ensino e da cultura, não tem correspondido aos anseios, expectativas e necessidades da maioria dos indivíduos da sociedade na qual está inserida. Temos ainda hoje, na iminência da entrada de um novo milênio, a escola homogeneizadora, racionalista e disciplinadora da década de 30 . Parece que a escola não acompanhou na mesma velocidade o desenvolvimento de outros setores da sociedade, de certa forma estagnou, sendo vista hoje como uma instituição em crise. Entretanto, é importante salientar que o fracasso escolar é, de certa forma, decorrente da organização social no modo de produção capitalista.

Tais fatos denunciam a crise da Escola. A Educação Física Escolar, que não está alheia a essa realidade, coloca-se necessariamente em discussão,

a intelectualidade da Educação Física brasileira parece acordar apenas a partir dos anos 70 para uma reflexão sobre a crise em suas áreas pedagógica e de pesquisa. ${ }^{9}$

$\mathrm{O}$ amplo debate se instaura $\mathrm{e}$

Desde o início dos anos 80, qualquer observador da área pode constatar que em vários estados do pais pululam núcleos empenhados na rediscussão de temas que vão desde a redefinição do papel da Educação Física brasileira até questões ligadas às mudanças necessárias ao nível da prática efetiva nas quadras, ginásios e campos. $^{10}$

Portanto, a Educação Física, enquanto disciplina integrante do currículo escolar, tem sido avaliada e questionada pela sociedade, assim como discutida pela sua comunidade científica, que tenta encontrar sua identi-

\footnotetext{
${ }^{9}$ MOREIRA, Wagner Wey. Por uma concepção sistêmica na pedagogia do movimento. In MOREIRA (org.). Educação Física \& Esportes: perspectivas para o século XXI. Campinas, SP: Papirus, 1992. p.203.

${ }^{10}$ GHIRALDELLI JÚNIOR, Paulo. Educação Física Progressista-A Pedagogia crítico-social dos conteúdos e a Educação Física brasileira. São Paulo, SP: Loyola, 1988. p.15.
} 
dade. A última década foi marcada pela chamada "crise" da Educação Física, quando se intensificou o questionamento sobre o ensino dessa disciplina na escola brasileira. A partir de então, procurou-se buscar uma identidade própria para a Educação Física, que não se caracterizava nem como disciplina, tampouco como área de conhecimento ou matéria essencial, mas sim como atividade, embora regulamentada por lei.

As questões pertinentes à prática da Educação Física sempre tiveram suas bases em leis e decretos que a legalizaram sem, no entanto, a legitimarem. A falta de legitimidade decorre, também, da ausência de organização de uma matriz teórica que a identifique, resgatando sua legitimidade social a partir de sua construção histórica e da definição do corpo teórico que lhe seja próprio e específico. Para Bracht,

Em termos gerais procurou-se legitimar a Educação Física via: a) contribuição para o desenvolvimento da aptidão física para a saúde; b) contribuição para o desenvolvimento integral da criança e, neste sentido, a contribuição (específica) da Educação Física era principalmente sobre o 'domínio psicomotor' ou 'motor'; c) contribuição para a massi-ficação esportiva e detecção de talentos esportivos (a famosa base da pirâmide); d) a Educação Física trata de dimensões do comportamento humano que são básicas: o movimento e o jogo. ${ }^{11}$

A “crise” da Educação Física não pode ser vista e analisada como algo isolado, uma vez que, de certa forma, está relacionada com a crise pela qual passa a sociedade e a escola, que é um dos principais campos de intervenção da disciplina, sendo que a mediatização de seus conteúdos interfere no processo educacional de inúmeras crianças e jovens.

Da fase crítica que atravessa a Educação Física, muitas perspectivas surgem e conseqüentemente, muitos estudos e algumas tentativas de colocálas em prática, embora muitas vezes sejam atuações pedagógicas isoladas. Valores são questionados, práticas são revistas, pesquisas realizadas, a polêmica instaurada. Esse esforço dos profissionais da área significa um crescimento qualitativo para a disciplina e estarmos sintonizados com as discussões relativas à Educação Física é de suma importância para que possamos nos situar enquanto educadores.

[...] os periodos de crise são extremamente férteis porque abrem no-

\footnotetext{
${ }^{11}$ BRACHT, Valter. Educação Física e Aprendizagem Social. Porto Alegre, RS: Magister, 1992. p.47.

${ }^{12}$ BRANDÃO, Zaia (org.). A crise dos paradigmas e a educação. $2^{\mathrm{a}}$ ed. São Paulo, SP: Cortez, 1995. Coleção questões da nossa época; v. 35. p. 28-29.
} 
vas possibilidades ao pensamento. Neste sentido, eles permitem o surgimento de alternativas aos modos de pensar anteriores. Revelam também que, muitas vezes, o verdadeiro sentido do momento pelo qual passamos só pode ser estabelecido e avaliado a posteriori, em retrospecto, quando e se, de acordo com a terminologia de Kuhn, se instaurar um novo contexto de "normalidade.'.12

Historicamente, coube à Educação Física o aspecto disciplinador, militarista e homogeneizador. Entretanto, seria injusto enfatizar tais aspectos apenas à Educação Física, pois na década de 30 , a escola como um todo tinha tais características, era também profundamente nacionalista.

Para alguns estudiosos, a Educação Física correu paralela às tendências e concepções que acompanharam a Educação no Brasil, as quais foram estudadas e classificadas, sendo denominadas com terminologias diferentes, embora com leituras de certa forma semelhantes. ${ }^{13}$

A Educação Física surgiu num ambiente escolar que separava completamente corpo e mente, como elementos absolutamente distintos, onde os aspectos que diziam respeito ao corpo eram menosprezados e aqueles relacionados ao intelecto valorizados.
Podemos verificar tal concepção de indivíduo ainda presente muitas vezes na escola, colaborando para a desconsideração da Educação Física, enquanto disciplina curricular comparada às demais que compõem o universo escolar.

Para Platão, o corpo era visto como instrumento e cárcere da alma; a doutrina da instrumentalidade do corpo apregoava o enaltecimento do campo das idéias e o menosprezo a tudo que se referia ao corpo.

A partir de Descartes, a doutrina acima referida foi substituída. Passou a prevalecer o conceito de que o corpo e a alma constituíam duas instâncias diferentes e independentes - sendo a alma, por se tratar do mundo espiritual - superior ao corpo, que por sua vez pertence ao mundo material. Assim, temos como herança histórica para a Educação Física a dicotomia corpo-mente.

O dualismo cartesiano teve grande influência sobre o pensamento ocidental, levando-se a atribuir ao trabalho mental um valor superior ao do trabalho manual. Em relação a esses conceitos, vê-se a Educação Física trazendo arraigada em si o estigma do trabalho manual, ainda hoje menosprezado na sociedade por herança dos tempos coloniais, quando o trabalho físico era destinado apenas aos escravos e o trabalho inte-

${ }^{13}$ CASTELLANI FILHO, Lino. Educação Física no Brasil-a história que não se conta. $2^{\mathrm{a}}$ ed. Campinas, SP: Papirus, 1991. Paulo GHIRADELLI JÚNIOR, op. cit. 
lectual à elite dominante.

Será que hoje tais conceitos são diferentes na sociedade? Por outro lado, vê-se hoje a hipervalorização do corpo, enquanto aparência. Padrões de imagem do corpo são veiculadas das mais diferentes formas, o dualismo corpo-mente continua existindo às avessas, as mais diversas atividades físicas são praticadas pelas pessoas, objetivando conseguir um corpo padronizado.

Gonçalves declara:

Essa separação se faz sentir na Educação Física até os nossos dias, tanto na sua prática pedagógica como nas ciências que a embasam. Estas últimas se constituem em campos estanques, que não se intercomunicam; cada uma trata do corpo sob sua perspecti$v a$, como se esta fosse absoluta, ignorando a globalidade do homem. ${ }^{14}$

Será que hoje, na entrada de um novo milênio, o educando é visto na escola de maneira diferente? Será que é considerado em sua globalidade?

Freire nos diz:

Corpo e mente devem ser entendi- dos como componentes que integram um só organismo. Ambos devem ter assento na escola, não um (a mente) para aprender e o outro (o corpo) para transportar, mas ambos para se emancipar. Por causa dessa concepção de que a escola só deve mobilizar a mente, o corpo fica reduzido a um estorvo que, quanto mais quieto estiver, menos atrapalhará.[..] Sugiro que, a cada início de ano letivo, por ocasião das matrículas, também o corpo das crianças seja matriculado. ${ }^{15}$

Na escola, de certa forma, a criança e o jovem são destituídos de seus poderes motores. Concorda-se com o autor no sentido de que a escola visualiza o educando dicotomicamente, considerando que ou só sua mente aprende ou só o corpo, assim como valoriza mais o aspecto cognitivo em relação ao motor, ao social, ao afetivo, no processo educacional.

Moreira destaca essa valorização, ao afirmar:

A tradição educativa positivista, hegemônica ainda hoje em nossas escolas, advoga uma educação racional, abstrata, individualizante,

${ }^{14}$ GONÇALVES, Maria Augusta Salim. Sentir, Pensar, Agir. Corporeidade e Educação. Campinas, SP: Papirus, 1994. p. 51.

${ }^{15}$ FREIRE, João Batista. Educação de corpo inteiro-teoria e prática da Educação Física. São Paulo, SP: Scipione, 1989. p. 13-14.

${ }^{16}$ MOREIRA, Wagner Wey. Perspectivas da Educação Motora na Escola. Texto apresentado no $I^{\circ}$ Congresso Brasileiro de Educação Motora. Campinas, SP: FEF/UNICAMP, 1994. p. 3. 
onde os educandos evoluem por suas próprias potencialidades. Entenda-se ainda potencialidade como capacidade de memorização dos conteúdos já ministrados e definidos, numa ênfase à idéia, ao privilégio cognitivo, em detrimento do corpo como um todo. ${ }^{16}$

Hoje se discute e perspectiva-se a educação escolar visualizando o educando como um todo. Questões fundamentais são abordadas, mas no cotidiano percebem-se poucas mudanças, a escola continua sendo homogeneizadora, racionalista e disciplinadora.

A educação escolar precisa ser repensada. A Escola é vista atualmente como uma instituição, em crise que é discutida e analisada pela comunidade científica. Portanto, a Educação Física não poderia estar bem numa escola que vai mal.

Quem é o professor de Educação Física nessa escola em crise? Quais são os conteúdos da Educação Física Escolar (em crise) nela desenvolvidos? De que forma o professor conduz sua prática pedagógica escolar cotidiana? Como tornar a Educação Física Escolar significativa?

Temos que reconhecer que apesar de a Escola e a Educação Física não estarem bem, ainda é esta que, enquanto disciplina ou atividade (não cabe aqui a discussão), se diferencia das demais. O professor de Educação Física é o "diferente", proporciona "atividades e coisas diferentes" para os alunos, atividades que eles experimentam movimentando-se, o que é extremamente atrativo. A escola é um tanto monótona e entediante, pelo seu próprio aspecto formal; a criança e o jovem nela passam o maior número de horas sentados. $\mathrm{O}$ professor de Educação Física acaba sendo uma das exceções na escola, pois as aulas de Educação Física constituem talvez a maior chance que os alunos têm para se movimentar.

Entre os estudos que tratam da crise da Educação Física, esta foi identificada de uma forma mais abran-gente naqueles realizados por Par-lebas ${ }^{17}$, que generaliza essa crise em todos os seus setores: das suas técnicas (conteúdos transmitidos), da formação de futuros profissionais (faculdades e universidades), da investigação (pesquisa), de intervenção (aplicação). Nos setores de intervenção, onde a Educação Física é desenvolvida e aplicada, o autor assim denomina e diferencia: a escola e a educação, o esporte de competição, o imenso campo do esporte de lazer, a educação física especial e a reeducação.

Parlebas diz que a divisão das técnicas, dos conhecimentos e da for-

\footnotetext{
${ }^{17}$ PARLEBAS, Pierre. Perspectivas para una Educacion Física Moderna. Andalucia: Quisport, 1988.

${ }^{18}$ Idem, op.cit.
} 
mação dos futuros profissionais evidencia uma fragmentação da Educação Física em uma multidão de práticas e em uma quantidade enorme de concepções. À medida que essa fragmentação aumenta, a Educação Física vai perdendo sua identidade. Por não haver conseguido afirmarse com coerência científica, a disciplina ficou submetida aos princípios regentes das ciências biológicas e das ciências humanas. Essas características de divisão e submissão representariam o destino da Educação Física. ${ }^{18}$ Outros estudiosos abordam algumas dessas questões de maneira às vezes diversa, embora considerem que as mesmas não deixam de ter uma certa relação com outras questões. Entre eles podemos citar Medina, cuja abordagem se relaciona parcialmente com a de Parlebas.

Para Medina, enquanto a crise atinge quase todos os setores da sociedade, que clamam por desenvolvimento, na Educação surgem os primeiros movimentos e inquietações para se repensar toda a estrutura educacional. $\mathrm{O}$ autor diz que tudo isso parece não estar perturbando muito a Educação Física, como se ela não fosse um processo educativo. Nesse sentido, ele declara:

A Educação Física precisa entrar em crise urgentemente. Precisa questionar criticamente seus valo- res. Precisa ser capaz de justificar-se a si mesma. Precisa procurar a sua identidade. É preciso que seus profissionais distinguam o educativo do alienante, o fundamental do supérfluo de suas tarefas. É preciso, sobretudo, discordar mais, dentro, é claro, das regras construtivas do diálogo. $O$ progresso, o desenvolvimento, o crescimento advirão muito mais de um entendimento diversificado das possibilidades da Educação Física do que através de certezas monoliticas que na verdade não passam, às vezes, de superficiais opiniões ou hipóteses. ${ }^{19}$

Parlebas refere-se à crise dizendo que a mesma se dá em vários setores da Educação Física. Embora o autor a tenha identificado de forma mais ampla, Medina faz uma abordagem num sentido mais genérico.

Quando Medina fala ser preciso distinguir nas tarefas da Educação Física o educativo e o fundamental (conteúdos significativos e contextualizados), do alienante e do supérfluo (conteúdos reproduzidos sem reflexão), pode-se fazer a relação com a crise que existe nos campos das técnicas (conteúdos e métodos de ensino) e da intervenção (entre eles, a escola) a que Parlebas se refere. Medina afirma que o formando ou já profissi${ }^{19}$ MEDINA, João Paulo Subirá. A educação física cuida do corpo...e "mente": bases para a
renovação e transformação da educação física. $4^{\mathrm{a}}$ ed. Campinas, SP: Papirus, 1985. p. 35 . 
onal, ao encontrar seu espaço no mercado de trabalho, procura atender as exigências desse mercado, adaptandose a ele sem questionar ou refletir. Podemos dizer que tal procedimento está relacionado com o tipo de formação acadêmica desse profissional e, de certa forma, com a crise no campo da investigação (pesquisa), refletindo-se assim em todos os outros procedimentos. É preciso, pois, avaliarmos o que se têm feito, investigarmos para detectarmos problemas, para então perspectivarmos mudanças.

A crise, ao mesmo tempo que, detecta e traz à tona problemas que perturbam o desenvolvimento de algo, ocasionando a desestabilização, possibilita a perspectiva de novos caminhos que poderão contribuir para a evolução e crescimento do objeto em questão. Ela nos faz refletir, obriga-nos a buscar novos caminhos, é um ponto de transição que tanto pode ocorrer, entre uma época de prosperidade $\mathrm{e}$ outra de depressão, como o contrário. Estarmos cientes de que a crise existe, já é o começo, o primeiro passo.

Por conseguinte, o momento de crise pela qual a Educação Física passa, pode e deve ser um momento de busca e de construção de sua identidade.

No final da década de 70 e início dos anos 80, configurou-se a necessidade de uma mudança de rumos na Educação Física brasileira. Aumentou significativamente o número de profissionais da área empenhados na discussão de 'práticas alternativas', para a Educação Física. Cresceu também o número de encontros regionais de profissionais da área preocupados com a conquista de uma 'Educação Física Crítica' etc. ${ }^{20}$

Um amplo debate, desde a época citada, envolve a Educação Física e a escola, numa perspectiva crítica, tratando da crise escolar que se desenvolve de forma paralela ao debate sobre a Educação. Têm sido realizados vários congressos, encontros, debates e trabalhos científicos, que objetivam romper com algumas visões da Educação Física como: "convencional", "biológica", "biologizante" entre outras. ${ }^{21}$ A Educação Física vem sendo alvo da crítica, principalmente por visualizar no indivíduo apenas seu aspecto biológico, objetivando a performance e o rendimento motor.

Estudos foram realizados (Betti, Bracht, Carmo, Castellani Filho, Cavalcanti, Ferreira, Freire, Ghiraldelli, Medina, Moreira, Oliveira, Santin...) e a literatura ganhou novas colaborações: questionadoras, divergentes, polêmicas. Alguns preocupados com a

\footnotetext{
${ }^{20}$ Paulo GHIRALDELLI JÚNIOR, op. cit., p. 45-46.

${ }^{21}$ Os referidos termos são utilizados respectivamente por: João Paulo Subirá MEDINA, 1983; Valter BRACHT, 1986; Lino CASTELLANI FILHO, 1988.
} 
necessidade de uma identidade para a Educação Física, outros tentando encontrá-la, havendo ainda aqueles que destacam a urgência de uma maior significância da Educação Física enquanto disciplina escolar.

Com a crítica, muitas questões são levantadas, tais como: Qual a identidade da Educação Física? O Esporte educa? O Tecnicismo promove uma seletividade? A Educação Física apenas reproduz os valores dominantes?

Dessas e outras questões e interpretações surgem muitas conclusões, algumas das quais ganham destaque. Bracht (1988) diz que a ideologia burguesa é veiculada pela Educação Física, que acaba não se configurando em propostas em nível da prática pedagógica. Ferreira (1984) fala sobre a não-diretividade do ensino, e o estímulo à crítica e à criatividade. Há aqueles que dizem da necessidade da Educação Física estar voltada à maioria da população (Castellani Filho, 1988 e Carmo, 1988). Betti (1988), Oliveira (1988), Freire (1989), Moreira $(1991,1992)$ fazem diferentes abordagens críticas em relação à Educação Física Escolar.

Alguns estudos, como os de Moreira, não ficam só numa análise crítica da Educação Física Escolar observada, mas procuram alertar os educadores de forma geral, para a necessidade de uma Educação en- quanto fenômeno humano, que considere

[...] o princípio de uma aprendizagem humana e humanizante, onde em sua complexidade estrutural, o homem pode ser fisiológico, biológico, psicológico e antropológico. Só que o corpo do homem não é um simples corpo, mas necessariamente um corpo humano, que só é compreensível através de sua integração na estrutura social. ${ }^{22}$

Freire, em algumas de suas abordagens, critica severamente os procedimentos utilizados na Escola, na aprendizagem de crianças; em outras, denuncia as dualidades existentes em nossa tradição intelectual e cultural, procurando superar a idéia do sensível versus inteligível. Diz que ambos são alojados no corpo, e se um dos dois faltar, é o mesmo que faltar o todo. ${ }^{23}$

Os referidos autores focalizam questões fundamentais relacionadas à Educação, ao movimento e ao homem como um todo, ressaltando que o educador precisa estar atento a essas questões.

Apesar do esforço empreendido por pesquisadores na área, há uma carência em turmas de prática pedagógica escolar da Educação Física.

\footnotetext{
${ }^{22}$ MOREIRA, Wagner Wey. Perspectivas da Educação Motora na Escola. p. 3-4.

${ }^{23}$ Ver João Batista FREIRE, op. cit. Idem, De corpo e alma: o discurso da motricidade. São Paulo, SP: Summus, 1991.
} 
Parece que aqueles que atuam na escola diretamente com a prática da disciplina têm dificuldades na compreensão da crise escolar e, por decorrência, da própria Educação Física. A Educação Física Escolar cotidiana parece estar alheia a toda problemática, continua acontecendo da mesma forma, como se teoricamente estivessem sendo discutidas questões que se referem a uma outra Educação Física que não ela.

Apesar de algumas tentativas isoladas, o quadro da Educação Física escolar, no momento, assim se apresenta: sem identidade, acrítica, transmitindo e controlando o ritmo das atividades mecânicas, desenvolvendo conteúdos ao sabor dos modismos, buscando a perfeição do gesto e descompromissada com o indivíduo e com a sociedade. ${ }^{24}$

A crise da Educação Física é uma parte da crise da escola; logo, para entendê-la não podemos nos ater apenas às suas particularidades. É necessário, analisarmos seus determinantes na sociedade na qual está inserida.

A crise da escola é a manifestação da maioria dos problemas presentes na crise da sociedade, que os alunos trazem para dentro da instituição educa- cional. Os alunos não chegam "vazios" na escola, trazem consigo problemas, expectativas e conhecimento.

Freire declara:

A criança não chega na escola zerada. É agressiva, amorosa, invejosa, tímida ou violenta. Pode ter muitas virtudes e defeitos, mas teria que aparecer do jeito que é. A partir disso, a escola faria um trabalho de educação. Se não se considera a individualidade da criança, a culpa é da escola. Por isso precisa mudar. Não se pode ter medo de ver a criança como ela é. Um dos maiores problemas da criança, na escola, é a agressividade. Para tratar essa agressividade é preciso admiti-la. Tratar uma criança 'ideal' resultará em frustração. ${ }^{25}$

Portanto, nos parece que tentar buscar soluções para a Educação Física Escolar apenas no interior da própria escola, sem a compreensão de elementos integrantes da realidade, é um tanto utópico.

\footnotetext{
${ }^{24}$ MOREIRA, Wagner Wey. Por uma concepção sistêmica na pedagogia do movimento. p. 204. ${ }^{25}$ FREIRE, João Batista. A escola desobediente. Revista da Fundação de Esporte e Turismo 1(3), 1989. p.13.
} 


\section{REFERENNCIAS BIBLIOGRÁFICAS}

1 BRACHT, Valter. Educação Física e Aprendizagem Social. Porto Alegre : Magister Ltda, 1992.

2 BRANDÃO, Zaia. (org). A crise dos paradigmas e a educação. $2^{\mathrm{a}}$ ed. São Paulo : Cortez/Autores Associados, 1995. Coleção questões de nossa época, v.35.

3 CASTELLANI FILHO, Lino. Educação física no Brasil: a história que não se conta. Campinas: Papirus, 1991. 2.ed.

4 CUNHA, D. A. As utopias da Educação. Rio de Janeiro : Paz e Terra, 1985.

5 FREIRE, João Batista. A escola desobediente. Revista da Fundação de Esporte e Turismo. v.1(3), 1989.

6 _. De Corpo e Alma: O discurso da motricidade. São Paulo : Summus, 1991.

7 — Educação de corpo inteiro: teoria e prática da Educação Física. São Paulo : Scipione, 1989.

8 GADOTTI, Moacir. Educação e poder: Introdução à pedagogia do conflito. São Paulo : Cortez/ Autores Associados, 1984.

9 GHIRALDELLI JÚNIOR, Paulo. Educação física progressista: A Pedagogia crítico-social dos conteúdos e a Educação Física Brasileira. São Paulo : Loyola, 1988.

10 GONÇALVES, Maria Augusta Salim. Sentir, pensar, agir: corporeidade e educação. Campinas : Papirus, 1994.
11 LIBÂNEO, José Carlos. Democratização da Escola Pública: a pedagogia crítico-social dos conteúdos. $9^{a}$ ed. São Paulo : Loyola, 1990.

12 MEDINA, João Paulo Subirá. A educação física cuida do corpo... e "mente": bases para a renovação e transformação da educação física. $4^{\mathrm{a}}$ ed. Campinas : Papirus, 1985.

13 MOREIRA, Wagner Wey. Educação Física Escolar: a busca da relevância. In PICCOLO (org). Educação Física Escolar: ser...ou não ter? Campinas : UNICAMP, 1993.

14 — . (org). Educação Física \& Esportes: Perspectivas para o século XXI. Campinas : Papirus, 1992.

15 —. Perspectivas da Educação Motora na Escola. In DE MAR$\mathrm{CO}$, Ademir (org). Pensando a Educação Motora na Escola. Campinas : Papirus, 1995.

16 — - Por uma concepção sistêmica na pedagogia do movimento. In MOREIRA (org). Educação Física \& Esportes: Perspectivas para o século XXI. Campinas: Papirus, 1992.

17 OLIVEIRA, José Guilmar Mariz de; BETTI, Mauro; OLIVEIRA, Wilson Mariz de. Educação Física e o Ensino de $1^{\circ}$ grau: Uma abordagem crítica. São Paulo : EDU-EDUSP, 1988.

18 PARLEBAS, Pierre. Perspectivas para una Educacion Física Moderna. Andalucia : Quisport, 1988. 